\title{
The state of critical care ultrasound training in Europe: A survey of trainers and a comparison of available accreditation programmes
}

\author{
Laura Galarza1, 2 , Adrian Wong ${ }^{2,3}$, Manu L.N.G. Malbrain ${ }^{4-6}$ \\ ${ }^{1}$ Hospital General Univeristari de Castelló, Castelló de la Plana, Spain \\ ${ }^{2}$ on behalf of the European Society of Intensive Care Medicine NEXT Committee \\ ${ }^{3}$ John Radcliffe Hospital, Oxford, United Kingdom \\ ${ }^{4}$ Ziekenhuis Netwerk Antwerpen, ZNA Stuivenberg, Antwerpen, Belgium \\ 5 Intensive Care Unit, University Hospital Brussels (UZB), Jette, Belgium \\ ${ }^{6}$ Faculty of Medicine, Free University of Brussels (VUB), Brussels, Belgium
}

\begin{abstract}
Background: Although critical care ultrasound (CCUS) in the Intensive Care Unit has been increasing exponentially for diagnostic and therapeutic purposes, the lack of a uniform formal training structure and programme has posed the question of whether scans have been appropriately performed or reported, and whether there exists proper clinical governance to ensure a high standard of care.

Methods: An online survey was sent to the representatives of various national intensive care societies via the European Society of Intensive Care Medicine CoBaTrICE committee. A comparison between 5 worldwide accreditation programmes was also made.

Results: Twenty-seven out of 42 countries replied our survey. Five countries had a nationally accredited programme in ICM Echocardiography while six were in the process of developing one. Three countries had a CCUS-accredited programme. Most had local programmes. Transthoracic echocardiography, lung and vascular ultrasound were considered essential. Although CCUS training programmes should incorporate a combination of theoretical and practical teaching, it is not clear which is the best format.

The main barriers to delivering CCUS training included a lack of formally agreed competencies, as well as a lack of trainers and time. There is also a lack of agreement between the five accreditation programmes.

Conclusions: There is a need for a well-structured and competent CCUS training program. The use of ultrasound in critical care for diagnostic and therapeutic purposes has been increasing exponentially. Once the remit of radiologists and cardiologists, point-of-care ultrasound and focused echocardiography is becoming an increasingly routine instrument for all acute specialties including intensive care medicine, despite the lack of evidence that it improves patient mortality in the ICU setting.
\end{abstract}

Anaesthesiology Intensive Therapy 2017, vol. 49, no 5, 382-386

Key words: critical care ultrasound, training, echocardiography

As the list of diagnostic and therapeutic interventions is large, most critical care ultrasound (CCUS) programmes tend to be more focused examinations compared to that performed by radiologists. This approach has been adopted by most acute specialties, including Emergency Medicine.
The Royal College of Radiologists has published guidelines for non-radiologists wanting to train in ultrasound [1]. It recognises the increasing availability of ultrasound and acknowledges the role it plays in the diagnosis and management of patients; thus, clinicians now use ultrasound evalu- 


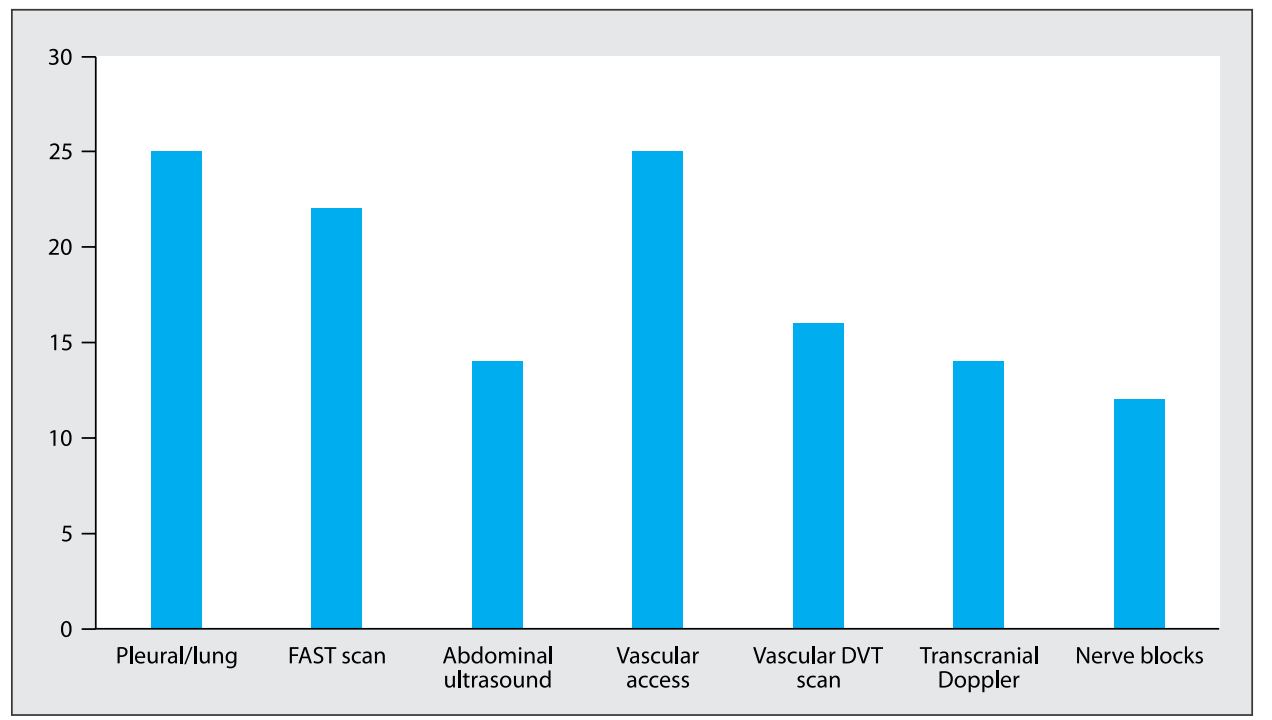

Figure 1. Modules that should be included in CCUS programmes (Y-axis indicates number of respondents)

ation as an extension of the bedside clinical examination. Hence, CCUS may become the modern stethoscope of the bedside critical care physician [2].

Although championed by enthusiasts, the use of CCUS has lagged behind that of other acute specialties. Two international expert statements have acknowledged the challenges of obtaining appropriate training in echocardiography and CCUS $[3,4]$, and further described the components of competence with specific goals of training and skill development. Despite this, the lack of a uniform formal training structure and programme is a recurring issue worldwide, posing the question of whether scans have been appropriately performed/reported, and whether there exists proper clinical governance to ensure a high standard of care.

The aim of our survey was to ascertain the current state of CCUS training in Europe. We also compared the available accreditation programmes worldwide and the perceived barriers for colleagues in accessing CCUS training.

\section{METHODS}

An online survey was sent to the representatives of various national intensive care societies via the European Society of Intensive Care Medicine CoBaTrICE Committee. Members of the committee play a role in Intensive Care Medicine (ICM) training and programme development at national level. The survey addressed several areas of interest including the current state of training, modules included and accreditation process and also where they perceived barriers to training in CCUS. The survey was conducted over a 6-month period between February and July 2016, allowing for 2 rounds of reminders to be sent to the representatives. The results were analysed using Google Form.
Five widely publicised CCUS accreditation programmes were analysed. Comparisons were made with regard to modules, training format, duration and assessment.

\section{RESULTS}

Twenty-seven out of 42 countries contacted replied, giving a response rate of $64 \%$. These included the larger Western European countries such as France, Spain, Italy, UK and Germany.

Only five countries had a nationally accredited programme in ICM Echocardiography. These were the UK, Italy, Netherlands, Germany and Spain. A further six countries were in the process of developing one. The lack of a formal accreditation programme did not mean that trainees were not exposed to echocardiography with a further five countries incorporating them into their ICM training programme. The majority of respondents (81\%) had access to locally delivered trans-thoracic echocardiography (TTE) courses. Although $92.6 \%$ of respondents felt that TTE was an essential skill for Intensivists, only $40.7 \%$ thought that transoesophageal echocardiography (TOE) was.

With regards to general CCUS only three countries had a national accreditation programme, namely the United Kingdom, Spain and the Netherlands.

There was variation in which modules the respondents felt should be included in a CCUS training programme (Fig. 1). Lung ultrasound and vascular ultrasound for obtaining access were considered essential. Transcranial Doppler and ultrasound-guided nerve blocks were deemed less important. Opinions regarding abdominal ultrasound training were divided in terms of its relevance to clinicians and what should be included in a training programme (Fig. 2). 


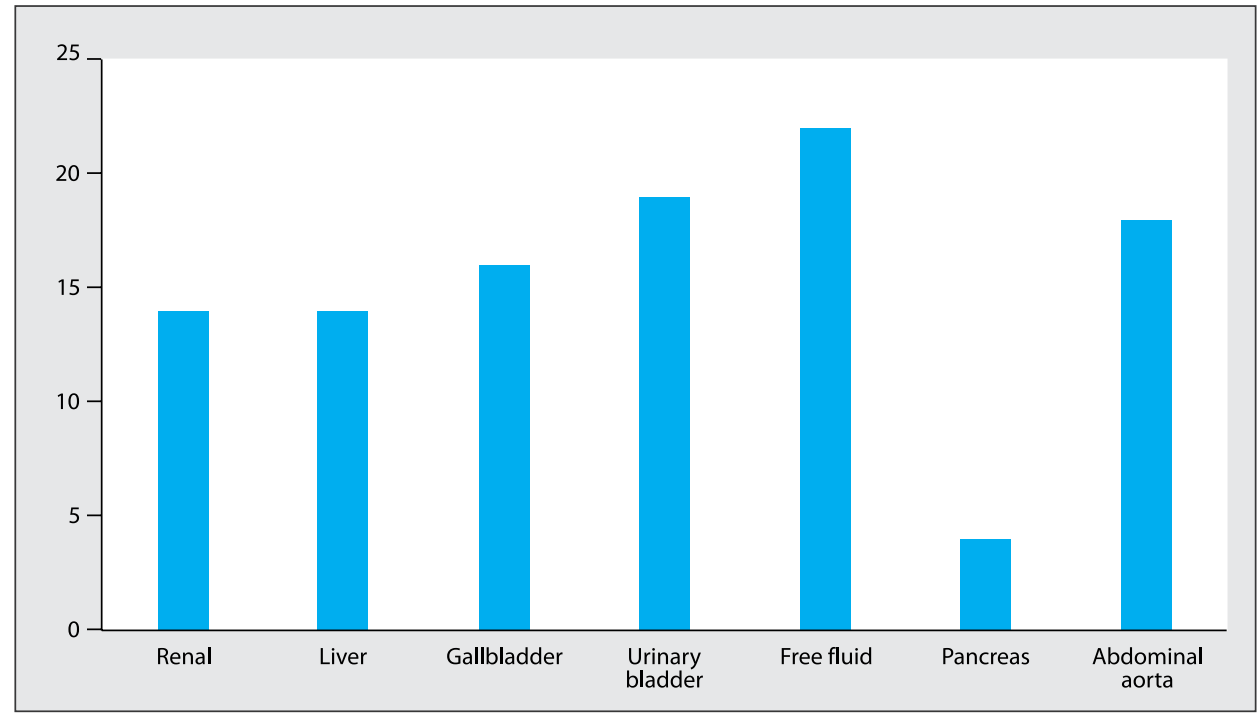

Figure 2. Submodules that should be included in the abdominal module of CCUS programmes (Y-axis indicates number of respondents)

Table 1. Accreditation programmes in point-of-care ultrasound

\begin{tabular}{|c|c|c|c|c|c|}
\hline & UK & ACCP & SCCM & ESICM & Canada \\
\hline Duration & 1 year & 3 years & Not specified & Max. 2 years & Not specified \\
\hline $\begin{array}{l}\text { Theoretical } \\
\text { programme }\end{array}$ & $\begin{array}{c}1 \text { day echo } \\
1 \text { day CCUS } \\
\text { online module }\end{array}$ & $\begin{array}{l}2 \text { courses }+1 \text { online } \\
\text { module }\end{array}$ & 20 hours & $\begin{array}{l}10 \text { hours echo } \\
10 \text { hours CCUS }\end{array}$ & $\begin{array}{l}10 \text { hours echo } \\
10 \text { hours CCUS }\end{array}$ \\
\hline Logbook & Yes & Yes & Yes & Yes & Yes \\
\hline TTE & 50 studies & $\begin{array}{l}10 \text { studies } \\
\text { (50 images) }\end{array}$ & 30 studies & 30 studies & 30 studies \\
\hline Lung/pleural & 50 studies & $\begin{array}{c}4 \text { studies } \\
\text { (12 images) }\end{array}$ & 20 studies & Not specified & 20 studies \\
\hline Abdominal & 20 studies & $\begin{array}{c}4 \text { studies } \\
\text { (16 images) }\end{array}$ & 30 studies & Not specified & 25 studies \\
\hline Vascular access & 5 studies & Not specified & 20 studies & Not specified & 10 studies \\
\hline Assessment & $\begin{array}{c}\text { Yes - at end of each } \\
\text { module }\end{array}$ & $\begin{array}{l}\text { Yes - at completion } \\
\text { of entire portfolio }\end{array}$ & $\begin{array}{l}\text { Variable for credentialing } \\
\text { external bodies for } \\
\text { certification }\end{array}$ & Not specified & Yes \\
\hline
\end{tabular}

Abbreviations in the text

Respondents agreed that a CCUS training programme should incorporate a combination of theoretical and practical teaching. A logbook should be kept while $74 \%$ of respondents felt that a formal assessment is required to ensure competencies. The main barriers to delivering CCUS training included a lack of formally agreed competencies, as well as a lack of trainers and time. Resistance from specialities outside of ICM was also highlighted.

Five programmes were identified (Table 1):

- American College of Chest Physicians (ACCP) Critical Care Ultrasonography [5]

- Society of Critical Care Medicine programme (SCCM) $[6,7]$

- Canadian Intensive Care Society programme [8]
- Core Ultrasound Skills in Intensive Care (CUSIC) and Focused Intensive Care Echocadiography (FICE) programme $[9,10]$

- European Society of Intensive Care Medicine (ESICM) [3]

\section{DISCUSSION}

There is little doubt that CCUS is a useful tool for Intensivists. Our survey has shown that there is considerable variation in access to CCUS training in the various national ICM training programmes and how training is delivered across Europe.

Although critical care echocardiography is more established compared to general CCUS, only five countries had an established, formal accreditation programme for TTE. 
Despite this, it was considered an essential skill by over $90 \%$ of respondents. This is further evidenced by the fact that despite the lack of formal accreditation, exposure to TTE is incorporated into the training programmes of $46 \%$ of respondents with a further $17 \%$ currently developing programmes. Locally-organised TTE courses and training are available in the countries of $84 \%$ of the respondents. Unsurprisingly, TOE is less well-established, being more invasive than TTE. The expertise required to deliver TOE training to the appropriate level and logistical considerations make this module more challenging to acquire compared to TTE.

General CCUS was less accessible and only three countries had formally adopted a national accreditation programme into their ICM training. Lung and vascular access ultrasound were the most well-established. More divisive is the abdominal access which is probably the ultrasound modality most established outside radiology and cardiology. Indeed, the use of ultrasound in resuscitation such as the Focussed Abdominal ultrasound Scan in Trauma (FAST scan) is part of the skillset of most emergency physicians. Given the extensive list of intra-abdominal pathology that can be diagnosed on ultrasound, there was a lack of agreement as to what should be included into the list of competencies.

Our survey also highlighted the barriers to delivering a high quality-training programme for CCUS. The lack of trainers, time and agreed set of competencies have been particularly highlighted. For countries such as the UK, with established accreditations for critical care echocardiography (FICE) and general CCUS (CUSIC), there remains the challenge of the lack of trainers which limits its incorporation into the national ICM training programme.

Opponents to the extended use of ultrasound outside of Radiology (or echocardiography outside of Cardiology) have raised concerns about the competencies of clinicians to perform and interpret such scans. Hence, the issue of training and accreditation is vital. Our survey has shown that there is considerable variation in the delivery of CCUS across Europe and indeed worldwide. The problem is further compounded by the absence of an agreed method on how best to train physicians in CCUS. It is crucial that such competencies are agreed upon to ensure robust clinical governance.

We compared five accreditation programmes in pointof-care ultrasound specifically focused for the critical care setting. There were three from the Americas, namely: the American College of Chest Physicians CCUS; the Society of Critical Care Medicine programme; and the Canadian Intensive Care Society programme. Two programmes were identified from Europe, namely: the Core Ultrasound Skills in Intensive Care (CUSIC) programme from the UK; and the European Society of Intensive Care Medicine. There are other programmes available such as the WinFocus programme [11] which is not country-specific. Common themes across the programmes included the need for didactic teaching, direct supervision and maintenance of a logbook.

Delivery of didactic teaching varies between face-toface courses and online teaching modules, and differ in their duration and structure. Although online teaching modules can improve accessibility to CCUS training, they do not address the issue of the shortage of trainers. Hands-on supervision early on in the learning curve is invaluable; without a critical mass of trainers, accessibility to CCUS will remain a challenge.

Within the different modules, the programmes again differ as to which competencies should be included. As an example, the abdominal module in the UK accreditation involves assessment of free fluid and urinary bladder scans. The Canadian programme includes renal ultrasound for the assessment of hydronephrosis and abdominal aortic scanning.

Other differences are the minimum number of scans and assessments between the programmes. These variations and lack of consensus need to be addressed to ensure that clinicians are competently trained. National bodies and large specialty organisations such as the Society of Critical Care Medicine and the European Intensive Care Society should play a role in this area.

\section{CONCLUSION}

Our survey provides a detailed analysis of the state of CCUS training in Europe. It highlights significant variation in the various programmes and the barriers to delivering training. When comparisons were made between prominent accreditation programmes, we noted significant variations in the delivery and expected competencies. Such issues need to be addressed before CCUS can be included in national ICM training programmes.

\section{ACKNOWLEDGEMENTS}

1. The authors would like to acknowledge the support of the ESICM CoBaTrICE Committee. MLNGM is member of the medical advisory board of Pulsion Medical Systems (Maquet Getinge) and Holtech Medical and consults for Kinetic Concepts International and ConvaTec. He is co-founder of the International Fluid Academy (IFA). This article is endorsed by the IFA. The mission statement of the IFA is to foster education, promote research on fluid management and hemodynamic monitoring, and thereby improve the survival of the critically ill by bringing together physicians, nurses, and others from throughout the world and from a variety of clinical disciplines. The IFA is integrated within the not-for-profit charitable organization iMERiT, International Medical Education and Research Initiative, under Belgian law. The IFA website (http://www.fluidacademy.org ) is now an of- 
ficial SMACC affiliated site (Social Media and Critical Care) and its content is based on the philosophy of FOAM (Free Open Access Medical education — \#FOAMed). The site recently received the HONcode (Health on the Net) quality label for medical education (https://www.healthonnet. org/HONcode/Conduct.html?HONConduct519739). The other authors have no possible conflicts of interest with regard to the contents of this paper.

2. Source of funding: none.

3. Conflict of interest: none.

\section{References:}

1. Ultrasound training recommendations for medical and surgical specialties. Royal College of Radiologists. 2nd Edition. 2012.

2. Lichtenstein $D$, van Hooland $S$, Elbers $P$, et al. Ten good reasons to practice ultrasound in critical care. Anaesthesiol Intensive Ther. 2014; 46(5): 323-335, doi: 10.5603/AIT.2014.0056, indexed in Pubmed: 25432552.

3. Expert Round Table on Ultrasound in ICU. International expert statement on training standards for critical care ultrasonography. Intensive Care Med. 2011; 37(7): 1077-1083, doi: 10.1007/s00134-011-2246-9, indexed in Pubmed: 21614639.

4. Mayo PH, Beaulieu Y, Doelken $P$, et al. American College of Chest Physicians/La Société de Réanimation de Langue Française statement on competence in critical care ultrasonography. Chest. 2009; 135(4): 1050-1060, doi: 10.1378/chest.08-2305, indexed in Pubmed: 19188546.

5. American College of Chest Physicians Critical Care Ultrasonography Programme. http://www.chestnet.org/Education/Advanced-Clinical-Training/Certificate-of-Completion-Program/Critical-Care-Ultrasonography.

6. Pustavoitau A, Blaivas M, Brown SM, et al. From the Ultrasound Certification Task Force on behalf of the Society of Critical Care Medicine:
Recommendations for achieving and maintaining competence and credentialing in critical care ultrasound with focused cardiac ultrasound and advanced critical care echocardiography. Society of Critical Care Medicine. http://journals.Iww.com/ccmjournal/Documents/Critical\%20 Care\%20Ultrasound.pdf.

7. Frankel HL, Kirkpatrick AW, Elbarbary M. Guidelines for the appropriate use of bedside general and cardiac ultrasonography in the evaluation of critically III patients-part I: general ultrasonography. Crit Care Med. 2015; 43(11): 2479-2502, doi: 10.1097/CCM.0000000000001216, indexed in Pubmed: 26468699.

8. Arntfield R, Millington S, Ainsworth C, et al. Canadian recommendations for critical care ultrasound training and competency. Can Respir J. 2014; 21(6): 341-345, indexed in Pubmed: 25255460.

9. UK Core Ultrasound Skills in Intensive Care CUSIC programme. http:// www.ics.ac.uk/ics-homepage/accreditation-modules/cusic-accreditation/.

10. UK Focussed Intensive Care Echocardiography FICE programme. http://www.ics.ac.uk/ics-homepage/accreditation-modules/focused-intensive-care-echo-fice/.

11. World Interactive Network Focused on Critical Care Ultrasound (WINFOCUS). http://winfocus.org/.

\section{Corresponding author:}

Adrian Wong

Oxford University Hospitals

NHS Foundation Trust

John Radcliffe Hospital

Headley Way, Oxford OX3 9DU, UK

e-mail:avkwong@mac.com

Received: 15.09 .2017

Accepted: 13.11.2017 